\title{
Effects of Systemic, Intracerebral, or Intrathecal Administration of an $N$-Methyl-D-Aspartate Receptor Antagonist on Associative Morphine Analgesic Tolerance and Hyperalgesia in Rats
}

\author{
Gavan P. McNally and R. Frederick Westbrook \\ University of New South Wales
}

\begin{abstract}
A flavor paired with morphine shifted to the right the function relating morphine dose to tail-flick latencies and provoked hyperalgesic responses when rats were tested in the absence of morphine. These learned increases in nociceptive sensitivity were not mediated by alterations in tail-skin temperature. Microinjection of the competitive $N$-methyl-D-aspartate (NMDA) receptor antagonist D,L-2-amino-5-phosphonopentanoic acid (AP-5) into the lateral ventricle reversed the hyperalgesic responses but spared the tolerance to morphine analgesia. By contrast, systemic administration of the noncompetitive NMDA receptor antagonist MK-801 or intrathecal infusion of AP-5 reversed the hyperalgesic responses as well as the tolerance to morphine analgesia. The results demonstrate that associatively mediated tolerance to morphine analgesia can co-occur with hyperalgesic responses and are discussed relative to learned activation of endogenous pronociceptive mechanisms.
\end{abstract}

The spinal cord contains mechanisms that inhibit the activity of neurons that receive and transmit nociceptive information (see Willis \& Coggeshall, 1991, for a review). These mechanisms can be controlled by interconnected structures in the brainstem, most notably the periaqueductal gray in the midbrain and the nucleus raphe magnus in the medulla, which project to the dorsal horn via the dorsolateral funiculus (see Fields \& Basbaum, 1994, for a review). Opioid receptors located at each level play a key role in this descending pain control system, and binding at these receptors mediates the antinociceptive effects of opiate drugs such as morphine (see Yaksh, Al-Rodham, \& Jensen, 1988 , for a review). The spinal cord also contains pronociceptive mechanisms that facilitate the transmission of nociceptive information and mediate the hyperalgesia that results from tissue or nerve damage as well as from the malaise induced by agents such as $\mathrm{LiCl}$ or the bacterial endotoxin lipopolysaccharide (see Maier, Wiertelak, \& Watkins, 1992; Meller \& Gebhart, 1993; Watkins, Wiertelak, Goehler, et al., 1994; Wilcox, 1993). These pronociceptive mechanisms are also under descending control from the brainstem (e.g., Watkins, Wiertelak, Goehler, et al., 1994; Wiertelak, Furness, Horan, et al., 1994) and involve activity at excitatory amino acid receptors, in particular $N$-methyl-D-aspartate (NMDA) receptors, as well as intracellular processes linked

Gavan P. McNally and R. Frederick Westbrook, School of Psychology, University of New South Wales, Sydney, Australia.

This research was supported by grants from the Australian Research Council and the Government Employees Medical Research Fund and by an Australian Postgraduate Award. We are grateful to J. Harris for helpful comments on this article and to E. Milligan and D. Koski for advice on intrathecal surgery.

Correspondence concerning this article should be addressed to R. Frederick Westbrook, School of Psychology, University of New South Wales, Sydney 2052, Australia. Electronic mail may be sent tof.westbrook@unsw.edu.au. to NMDA receptor activation such as synthesis of nitric oxide and alterations in levels of protein kinase (for reviews, see Coderre, Katz, Vaccarino, \& Melzack, 1993; Meller \& Gebhart, 1993; McMahon, Lewin, \& Wall, 1993).

In addition to their activation by tissue damage or malaise, spinal pronociceptive mechanisms are recruited by repeated exposure to morphine. For instance, rats repeatedly exposed to morphine not only showed a reduction in levels of morphine analgesia as well as an increase in basal nociceptive sensitivity when tested in the absence of morphine. Importantly, this hyperalgesia was reversed by an intrathecal infusion of an NMDA receptor antagonist (Mao, Price, \& Mayer, 1994). The recruitment of spinal pronociceptive mechanisms may have mediated this reduction in the analgesic effectiveness of morphine by antagonizing spinal antinociceptive mechanisms. Support for this possibility has been provided by demonstrations that coadministrations of morphine with intrathecal infusions of either NMDA receptor antagonists or nitric oxide synthase inhibitors prevent the development and expression of morphine analgesic tolerance (e.g., Dunbar \& Yaksh, 1996; Elliott, Minami, Kolesnikov, Pasternak, \& Inturrisi, 1994; Grisel, Watkins, \& Maier, 1996; Marek, Ben-Eliyahu, Gold, \& Liebeskind, 1991; Marek, Ben-Eliyahu, Vaccarino, \& Liebeskind, 1991). These findings show that morphine analgesic tolerance and hyperalgesia can involve common mechanisms in the spinal cord.

In this research we investigated whether these mechanisms for morphine analgesic tolerance and hyperalgesia can be activated by associative learning processes. In the initial experiments we examined whether a flavor (saccharin) whose repeated presentations had been followed by injections of morphine would (a) shift to the right the function relating morphine dose to tail-flick latencies and (b) provoke hyperalgesia when rats were tested in the absence of morphine. In the remaining experiments we investigated the involvement of spinal and supraspinal NMDA receptors in 
associatively mediated tolerance and hyperalgesia. Specifically, rats were exposed to saccharin and tested for morphine analgesia and basal nociceptive sensitivity after systemic administration of MK-801 (Experiment 2), intracerebroventricular (Experiments 3a and 3b), or intrathecal (Experiments $4 \mathrm{a}$ and $4 \mathrm{~b}$ ) infusion of $\mathrm{D}, \mathrm{L}-2$-amino-5-phosphonopentanoic acid (AP-5). A flavor was selected to study these questions because rats suppress ingestion of a flavor whose presentation is followed by morphine injection. This suppression is mediated by morphine's action via the vagus (Bechara \& van der Kooy, 1985), which, in the case of emetic drugs such as $\mathrm{LiCl}$, is critical for their activation of spinal pronociceptive mechanisms (Watkins, Wiertelak, Furness, \& Maier, 1994; Watkins, Wiertelak, Goehler, et al., 1994; Wiertelak, Furness, Watkins, \& Maier, 1994) and, presumably, for the hyperalgesic effects of a LiCl-induced, averted flavor (Maier et al., 1992; Wiertelak, Smith, et al., 1994). Therefore, we reasoned that a flavor rendered aversive through its association with the effects of morphine in the gut also might gain access to these spinal pronociceptive mechanisms and thereby reduce morphine's analgesic effectiveness and provoke hyperalgesia.

\section{Experiments 1a, 1b, and $1 \mathrm{c}$}

In Experiments 1a-1c, we studied the effects of a morphine-averted flavor on the analgesic effectiveness of morphine and basal nociceptive sensitivity when rats were tested in the absence of morphine. After three occasions on which presentation of a saccharin solution was followed by injection of morphine (the paired group) or saline (the unpaired and naive groups), the rats were tested for morphine analgesia (Experiment 1a) and basal nociceptive sensitivity (Experiment $1 \mathrm{~b}$ ) in the tail-immersion test. The test for morphine analgesia used the dose-response methodology, such that dose-response curves (DRCs) were constructed for each group and the displacement and slope of these curves assessed. The DRC methodology was chosen because it is sensitive to small alterations in levels of morphine analgesia (Tiffany \& Maude-Griffin, 1988) and shifts in the dose-response function correspond more closely than single dose tests to pharmacological definitions of altered analgesic sensitivity (e.g., Kalant, LeBlanc, \& Gibbins, 1971). In Experiment 1c, rats in the paired and unpaired groups were tested for a period of $55 \mathrm{~min}$ after an injection of saline to assess any associatively mediated alterations in tail-skin temperature because interpretation of tail-flick data with reference to nociceptive modulatory circuitries can be confounded by an influence of tail-skin temperature on tail-flick latencies (e.g., Berge, GarciaCabrera, \& Hole, 1988; Hole \& Tjoslen, 1993; Tjolsen, Berge, Eide, Borch, \& Hole, 1988).

\section{Method}

\section{Subjects}

The subjects were experimentally naive male Wistar rats weighing between 300 and $400 \mathrm{~g}$. They were obtained from the colony of Specific-Pathogen-Free rats maintained by the Combined Universi- ties Laboratory Animal Services (Sydney, Australia). There were 80 rats in Experiment 1a, 24 rats in Experiment 1b, and 16 rats in Experiment 1c. Rats were housed in opaque, white plastic boxes $(65 \mathrm{~cm}$ long $\times 40 \mathrm{~cm}$ wide $\times 22 \mathrm{~cm}$ high) with 8 rats per box. The wire mesh roof of each box held food that was continuously available and (when scheduled) water bottles. The boxes were kept in a colony room maintained under natural lighting. The experiments were conducted between 9 a.m. and 5 p.m.

\section{Apparatus}

The colony room also contained eight black plastic boxes $(40 \mathrm{~cm}$ long $\times 20 \mathrm{~cm}$ wide $\times 15 \mathrm{~cm}$ high) with wire mesh roofs. Calibrated cylinders with stainless steel ball-bearing spouts were used to present fluids in these drinking boxes during the course of the experiments. The tail-flick apparatus consisted of a water bath whose temperature was controlled at a particular value $\left( \pm 0.5^{\circ} \mathrm{C}\right)$ by an open bath thermoregulator (Ratek Instruments, Melbourne, Australia). The water bath was located in a laboratory whose ambient temperature was maintained between $21^{\circ} \mathrm{C}$ and $23^{\circ} \mathrm{C}$. Tail-skin temperature was measured using a digital thermal probe (Anritsu, Tokyo, Japan). The laboratory also contained white plastic buckets $(26 \mathrm{~cm}$ diameter $\times 45 \mathrm{~cm}$ height) with air holes drilled in the lid and in the sides. These buckets served as chambers in which rats were kept in isolation from each other when they were brought to the laboratory.

\section{Drugs}

Morphine $\mathrm{HCl}$ was dissolved in sterile nonpyrogenic saline $(0.9 \% \mathrm{wt} / \mathrm{vol})$ to obtain concentrations of $1.25,2.5,5.0,7.5,10.0$, and $20.0 \mathrm{mg} / \mathrm{ml}$. This isotonic saline solution was used for control injections. Morphine and saline were injected intraperitoneally in a volume of $2.0 \mathrm{ml} / \mathrm{kg}$. During training, morphine was administered at a dose of $10.0 \mathrm{mg} / \mathrm{kg}$.

\section{Procedure}

Five days before the start of the experiment, each rat was handled for $1 \mathrm{~min}$ each day and placed on a fluid deprivation regimen that was maintained across the course of the experiment. The regimen consisted of allowing rats $20 \mathrm{~min}$ access to water at 6 p.m. each day in their home boxes in addition to the fluid obtained in the drinking boxes during experimental sessions. Rats were weighed daily across the course of the experiment.

Training. On Day 1 of the experiments, rats were placed in the drinking boxes and allowed 20 -min access to a $0.15 \%$ sodium saccharin solution (Sigma Chemical, Sydney, Australia). For rats in the paired group, saccharin consumption was followed immediately by an intraperitoneal injection of morphine, whereas for rats in the unpaired and naive groups, saccharin consumption was followed by an injection of saline. Immediately after the injection, all rats were returned to their home boxes. Eighteen hours later, on Day 2, all rats were removed from their home box, injected, and returned to their box. Rats in the paired and naive groups were injected with saline, whereas rats in the unpaired group were injected with morphine. Rats were given 20 -min access to water in the drinking boxes $6 \mathrm{hr}$ later. On Days 3 and 4, they received 20 -min access to water in the plastic boxes but did not receive any injections on these days. There were three of these 4-day cycles, so that there were 96-hr intervals between morphine injections for rats in the paired and unpaired groups and between saccharin presentations for rats in all groups. Each flavor-morphine pairing was separated by $96 \mathrm{hr}$ because previous findings have suggested that 
relatively long interdose intervals are conducive to the involvement of associative learning processes in morphine tolerance development (e.g., Tiffany \& Maude-Griffin, 1988).

Familiarization. Across Days 13-16, rats were transported to the laboratory. On arrival, rats were placed in the plastic buckets for $20 \mathrm{~min}$, removed, handled, and returned to the buckets. This handling was repeated three times at 5-min intervals to familiarize the rats with the procedures to be used on test.

Tail-fick test (Experiments $1 a$ and $1 b$ ). On Day 17, rats were transported to the laboratory and placed in the plastic buckets for $20 \mathrm{~min}$. Baseline tail-flick latencies were determined by taking the average of the last three out of four tail-flick trials spaced 5 min apart. For tail-flick testing, the distal 4-cm portion of the rat's tail was immersed in a water bath and latency to completely remove the tail recorded by stopwatch. Latencies were recorded by an observer who did not know the experimental conditions. A second observer recorded the latencies of randomly selected rats $(25 \%)$ in each experiment. The interobserver correlations were more than .95 . The water temperature was maintained at $53^{\circ} \mathrm{C}$ in Experiment $1 \mathrm{a}$ and $51{ }^{\circ} \mathrm{C}$ in Experiment $1 \mathrm{~b}$. A water temperature of $53^{\circ} \mathrm{C}$ was used for the test under morphine (Experiment 1a) to prevent ceiling effects, and a water temperature of $51{ }^{\circ} \mathrm{C}$ was used for the test under saline (Experiment 1b) to prevent floor effects. At the conclusion of each trial, tails were wiped with a flannel cloth. After baseline determination, rats received an intraoral infusion of saccharin $(0.3 \mathrm{ml})$ followed $5 \mathrm{~min}$ later by an injection of morphine (Experiment 1a) or saline (Experiment 1b). In Experiment 1a, rats in each of the three groups were tested at one of four doses of morphine: paired group $(5.0,10.0,20.0$, or $40.0 \mathrm{mg} / \mathrm{kg} ; 2.0 \mathrm{ml} / \mathrm{kg} ; n=7$ per dose); unpaired group $(2.5,5.0,10.0$, or $20.0 \mathrm{mg} / \mathrm{kg} ; 2.0 \mathrm{ml} / \mathrm{kg} ; n=7$ per dose); and naive group $(2.5,5.0,10.0$, or $15.0 \mathrm{mg} / \mathrm{kg} ; 2.0 \mathrm{ml} / \mathrm{kg}$; $n=6$ per dose). In Experiment $1 \mathrm{~b}$, rats in the paired, unpaired, and naive groups ( $n=8$ per group) were tested for tail-flick latency after an injection of $2.0 \mathrm{ml} / \mathrm{kg}$ saline. Tail-flick testing began $5 \mathrm{~min}$ after injection of morphine or saline and was repeated once every $5 \mathrm{~min}$ for another $50 \mathrm{~min}$.

Tail-skin temperature (Experiment 1c). Rats were transported to the laboratory and placed in the plastic buckets for $20 \mathrm{~min}$. Baseline tail-skin temperatures were determined by taking the average of the last three of four measurements spaced $5 \mathrm{~min}$ apart. Tail-skin temperature was measured $6 \mathrm{~cm}$ from the tip of the tail on the dorsal surface. After baseline determination, rats in the paired $(n=8)$ and unpaired $(n=8)$ groups received an intraoral infusion of saccharin $(0.3 \mathrm{ml})$ followed 5 min later by an injection of 2.0 $\mathrm{ml} / \mathrm{kg}$ saline. Tail-skin temperatures were measured $5 \mathrm{~min}$ later and repeated every $5 \mathrm{~min}$ for another $50 \mathrm{~min}$.

\section{Statistical Analyses}

In Experiment 1a, mean tail-flick latencies for tests 30-55 min postmorphine were analyzed using hierarchical multiple regression (Cohen \& Cohen, 1975). Tail-flick latencies were regressed on morphine dose and training manipulation (dummy coded via pairwise comparisons), and the interaction between these two variable sets to assess the parallelism of DRCs. The variables were forced into the equation in that order. Following Tiffany and Maude-Griffin (1988), this analysis was conducted with morphine dose transformed to a logarithmic scale. In Experiments $1 \mathrm{~b}$ and $1 \mathrm{c}$, sets of planned orthogonal contrasts were written and significance was determined controlling the decisionwise error rate $(\alpha=.05)$ for each contrast tested using the method outlined by Hays (1972). Repeated measures contrasts were written to assess linear trends across minutes of testing and the interactions between groups and linear trend and tested using a multivariate model (Boik, 1981).

\section{Results}

Figure 1 shows the mean saccharin intake on the third training trial for rats in the three groups in Experiments 1a-1c. Statistical analyses of these data confirmed that rats in the paired group had learned to suppress saccharin intake because they drank significantly less than rats in the unpaired and naive groups in Experiments 1a, $F(1,77)=$ 198.2 , critical $F$ value $\left(F_{\mathrm{c}}\right)=4.0$, and $1 \mathrm{~b}, F(1,23)=176.2$, $F_{\mathrm{c}}=4.3$, and significantly less than rats in the unpaired group in Experiment $1 \mathrm{c}, F(1,14)=893.2, F_{\mathrm{c}}=4.6$. There were no significant differences between the intakes of rats in the unpaired and naive groups $(F \mathrm{~s}<1.8)$ in Experiments 1a and $1 \mathrm{~b}$.

Baseline latencies to tail flick ranged from 4.0 to $4.5 \mathrm{~s}$ before the morphine test in Experiment 1a and from 5.1 to $5.3 \mathrm{~s}$ before the saline test in Experiment 1b. There were no significant differences between groups in baseline tail-flick latencies $(F \mathrm{~s}<1.9)$. The mean baseline tail-skin temperatures in Experiment $1 \mathrm{c}$ were $24.3^{\circ} \mathrm{C}$ and $24.4{ }^{\circ} \mathrm{C}$, which did not differ from each other $(F<1)$.
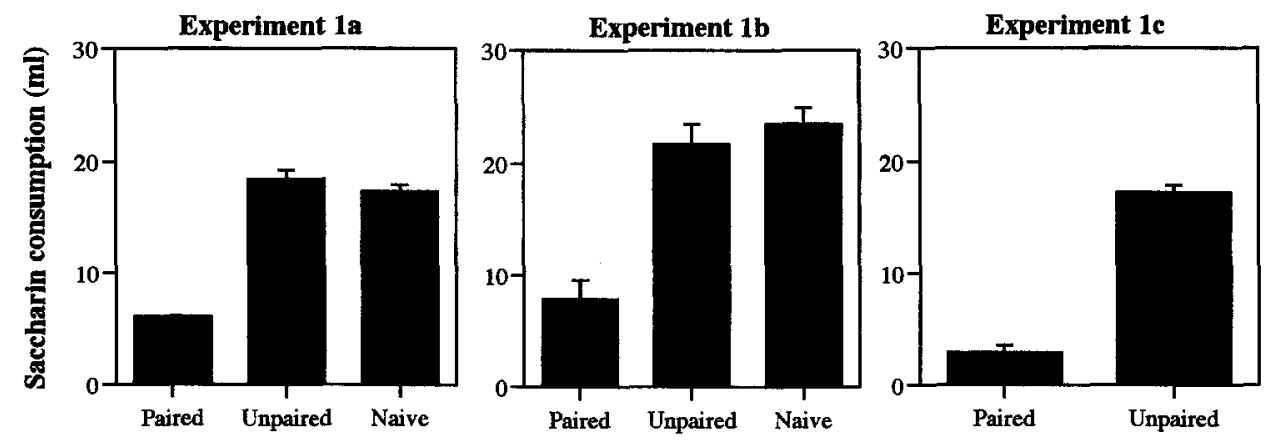

\section{Group}

Figure 1. Mean and standard error of the mean saccharin consumption during the third training trial for Experiment 1a (left panel), Experiment $1 \mathbf{b}$ (middle panel), and Experiment 1c (right panel). 
The mean tail-flick latencies from the trials conducted 30-55 min after injection of morphine for rats in the three groups in Experiment 1a are shown in Figure 2 (left panel). The straight lines represent the best-fitting lines obtained by regressing tail-flick latencies on morphine dose level for each group. Inspection of Figure 2 (left panel) suggests that the DRC for rats in the paired group was characterized by a parallel rightward shift compared with the performances shown by rats in the unpaired and naive groups. Furthermore, the DRC for rats in the unpaired group did not appear to differ either in displacement or slope from the performances of rats in the naive group. These observations were confirmed using multiple regression analysis, which revealed a significant effect of morphine dose $\left(R^{2}=.45\right), F(1$, 78) $=64.56, p<.0001$, an overall significant difference between the paired and unpaired groups $\left(\Delta R^{2}=.13\right), F_{\text {cha }}(1$, $78)=23.22, p<.0001$, and no overall difference in the DRCs of the unpaired and naive groups $\left(\Delta R^{2}=.0008\right)$, $F_{\text {cha }}(1,78)=0.14, p=.7060$. There were no significant differences between the slopes of the DRCs for paired and unpaired groups $\left(\Delta R^{2}=.005\right), F_{\text {cha }}(1,78)=0.94, p=.33$, confirming the parallel nature of the shift in DRC observed. There was also no evidence for a difference in the slope of the DRCs for the unpaired and naive group $\left(\Delta R^{2}=.004\right)$, $F_{\text {cha }}(1,78)=0.78, p=.3740$.

These results demonstrate that rats tested after intraoral infusion of a flavor previously paired with morphine displayed a reduction in sensitivity to morphine analgesia, as indexed by shifts in the function relating morphine dose to tail-flick latency. Specifically, the DRC for the paired group was characterized by a significant parallel rightward shift compared with the DRC for the unpaired group. Moreover, a history of morphine exposure per se did not influence sensitivity to morphine's analgesic effects because the DRC for rats in the unpaired group did not differ from that shown by rats in the naive group. Nor did that history alter tail-flick latencies across doses of the drug because there was no significant interaction between morphine dose and the differences between rats in the unpaired and naive groups.

The mean tail-flick latencies by rats in the three groups tested after a saline injection in Experiment $1 \mathrm{~b}$ are shown in Figure 2 (middle panel). Inspection of Figure 2 (middle panel) suggests that rats in the paired group responded with faster tail-flick latencies than those shown by rats in the unpaired and naive groups, whose latencies did not appear to differ from each other. The statistical analysis confirmed that the flavor that had been paired with morphine provoked hyperalgesia when it was followed by an injection of saline because rats in the paired group showed significantly faster latencies averaged across the 55-min test than did rats in the unpaired and naive groups, $F(1,21)=12.6, F_{\mathrm{c}}=4.3$. This hyperalgesia was not a consequence of a history of morphine per se because there were no significant differences between the tail-flick latencies of rats in the unpaired and naive groups $(F<1)$. Finally, there was no statistical evidence for an overall linear trend in tail-flick latencies across minutes of testing $(F<1)$, nor any interactions between the contrasts assessing differences between groups and minutes of testing $(F \mathrm{~s}<1)$.

The mean tail-skin temperatures across the 55-min test period for rats in the paired and unpaired groups in Experiment 1c are shown in Figure 2 (right panel). The statistical analysis confirmed what is obvious from Figure 2 (right panel), which is that an injection of saline after presentation of the saccharin did not differentially affect the tail-skin temperatures of rats in the paired group compared with those of rats in the unpaired group, $F(1,14)<1, F_{\mathrm{c}}=$ 4.6. The analysis also revealed that there was no evidence for a linear trend in tail-skin temperatures across minutes of testing averaged across groups $(F=1.9)$ or an interaction between minutes of testing and the contrast assessing differences between the paired and unpaired groups $(F<1)$.
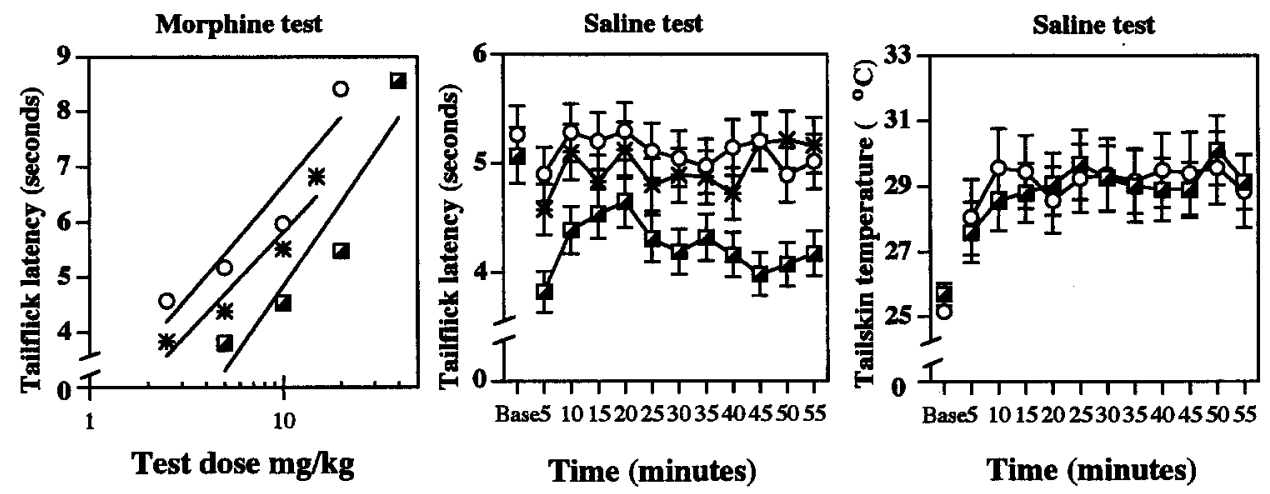

\begin{tabular}{|llllll|}
\hline$\square$ & Paired & $\circ$ & Unpaired & $*$ & Naive \\
\hline
\end{tabular}

Figure 2. Left panel: Mean tail-flick latencies after tail immersion in a $53^{\circ} \mathrm{C}$ waterbath during the morphine test in Experiment 1a. The straight lines represent the best-fitting lines obtained by regressing tail-flick latency on morphine dose level for each group. Middle panel: Mean and standard error of the mean tail-flick latencies following tail immersion in a $51^{\circ} \mathrm{C}$ waterbath during the saline test in Experiment 1b. Right panel: Mean and standard error of the mean tail-skin temperatures during the saline test in Experiment 1c. 
Despite failing to detect any differences between the paired and unpaired groups in tail-skin temperatures, inspection of Figure 2 (right panel) suggests that this measure was sensitive to variations in tail-skin temperature. Specifically, tail-skin temperatures for the paired and unpaired groups were elevated from baseline temperatures. To examine whether this measure was sensitive to alterations in tail-skin temperature, we compared baseline tail-skin temperatures for both groups with the average of the measurements taken across the 55-min test period. This analysis revealed that tail-skin temperatures were in fact elevated above baseline tail-skin temperatures, $t(14)=6.4, t_{\mathrm{c}}=2.2$. Thus, the failure to observe any difference in tail-skin temperature between rats in the paired and unpaired groups across the test period could not be attributed to the use of an insensitive measure. Accordingly, the differences in morphine responsivity and basal nociceptive sensitivity between these groups observed in Experiments $1 \mathrm{a}$ and $1 \mathrm{~b}$ are not readily interpreted as being a consequence of associatively mediated alterations in thermoregulation.

The results of these experiments confirm a role for associative learning processes in morphine analgesic tolerance development by showing that a flavor whose presentations had been followed by injection of morphine provoked a parallel rightward shift in the function relating morphine dose to tail-flick latency (e.g., Tiffany \& Maude-Griffin, 1988). They also reveal that this associatively mediated morphine tolerance was accompanied by hyperalgesia when rats in the paired group were presented with the flavor paired with morphine but tested under saline (e.g., Siegel, 1975). Furthermore, no differences in tail-skin temperature were detected between rats in the paired and unpaired groups despite the fact that this measure was sensitive to elevations in tail-skin temperature from baseline. Therefore, neither the learned reduction in morphine analgesia nor the production of hyperalgesia can be explained by reference to associatively mediated alterations in tail-skin temperature.

\section{Experiment 2}

In this experiment we investigated the involvement of NMDA receptors in the expression of associatively mediated morphine analgesic tolerance and hyperalgesia. Rats in the paired, unpaired, and naive groups were trained according to the same schedule as had been used previously and were tested after an intraoral infusion of saccharin on two occasions separated by $96 \mathrm{hr}$. The initial test was conducted under the influence of morphine and the second after a saline injection. We tested rats in this sequence because the initial test was consistent with the history of rats in the paired group as it entailed a further pairing of saccharin and morphine for those rats. On the initial (morphine) test, half the rats in each of the three groups received a systemic injection of the noncompetitive NMDA receptor antagonist MK-801, whereas the remainder were tested with its vehicle. On the second (saline) test, those rats tested initially with MK-801 were tested with vehicle, and rats initially tested with vehicle were now tested with MK-801.

\section{Method}

\section{Subjects and Apparatus}

Subjects were 48 experimentally naive male Wistar rats weighing between 300 and $400 \mathrm{~g}$. They were obtained from the same source and maintained under the conditions described previously. The apparatus was that used in the previous experiments.

\section{Drugs}

Morphine $\mathrm{HCl}$ was dissolved in sterile nompyrogenic saline $(0.9 \% \mathrm{wt} / \mathrm{vol})$ to obtain a concentration of $5.0 \mathrm{mg} / \mathrm{ml}$. This isotonic saline solution also was used for control injection. Morphine and saline were injected intraperitoneally in a volume of $2.0 \mathrm{ml} / \mathrm{kg}$, producing a training and test dose of $10.0 \mathrm{mg} / \mathrm{kg}$. (+)-MK-801 hydrogen maleate (Research Biochemicals, Natick, MA) was dissolved in a sterile nonpyrogenic saline solution $(0.9 \% \mathrm{wt} / \mathrm{vol})$ to obtain a concentration of $0.1 \mathrm{mg} / \mathrm{ml}$ and injected intraperitoneally in a volume of $1.0 \mathrm{ml} / \mathrm{kg}$. This dose was selected because it has been shown to prevent morphine analgesic tolerance development (Trujillo \& Akil, 1991).

\section{Procedure}

Five days before beginning the experiment, the rats were handled each day and placed on the fluid deprivation regimen described previously.

Training and familiarization. Across Days 1-12, rats in each of the three groups were trained in the manner described previously. Thus, rats in the paired group $(n=16)$ were injected with morphine after exposure to saccharin on Day 1 and with saline 18 hr later on Day 2, whereas rats in the unpaired group $(n=16)$ received a saline injection after exposure to saccharin on Day 1 and a morphine injection $18 \mathrm{hr}$ later on Day 2 . Rats in the naive group ( $n=16$ ) were injected with saline twice: after saccharin exposure on Day 1 and $18 \mathrm{hr}$ later on Day 2. On Days 2-4, all rats received 20 -min access to water in the drinking boxes. There were three of these 4-day cycles. Across Days 13-16, all rats were familiarized with the test apparatus in the manner described for Experiments 1a and $1 \mathrm{~b}$.

Tail-flick test under morphine. On Day 17, the rats were transported to the laboratory and placed in the plastic buckets for $20 \mathrm{~min}$. Baseline latencies were determined in the manner described for Experiment 1a with the waterbath maintained at $53^{\circ} \mathrm{C}$. Ten minutes after the final baseline trial, half of the rats in each group were injected with MK-801, whereas the remainder were injected with vehicle. Twenty five minutes later, all rats received an intraoral infusion of saccharin, which was followed 5 min later by an injection of morphine. Tail-flick testing began $5 \mathrm{~min}$ later and was repeated once every $5 \mathrm{~min}$ for another $50 \mathrm{~min}$.

Tail-flick test under saline. On Days 18-20, the rats received 20 -min access to water in the home boxes in the colony room. On Day 21, the rats were transported to the laboratory and tested again. The procedure was the same as that just described except that the rats were tested after a saline injection and the waterbath was maintained at $51^{\circ} \mathrm{C}$ to replicate the procedure used in Experiment $1 b$.

\section{Statistical Analysis}

The results of Experiments $1 \mathrm{a}$ and $1 \mathrm{~b}$ show that the differences between the tail-flick latencies for rats in the three groups were consistent across the test period. Accordingly, in this and subse- 
quent experiments, the tail-flick latencies were averaged across the test period before analysis. Sets of planned orthogonal contrasts were written to analyze the results of the tail-flick tests for this and the remaining experiments. Significance was determined in each experiment by controlling the decisionwise error rate $(\alpha=.05)$ for each contrast tested using the method outlined by Hays (1972).

\section{Results}

Statistical analysis confirmed that rats in the paired group had learned to suppress saccharin intake because they drank significantly less saccharin $(M=7.6 \mathrm{ml})$ on the third training trial than did rats in the unpaired $(M=19.8 \mathrm{ml})$ and naive $(M=19.0 \mathrm{ml})$ groups, $F(1,45)=129.6, F_{\mathrm{c}}=4.1$. The differences between the saccharin intakes for rats in the control groups were not significant $(F<1)$. The mean baseline latencies ranged from 3.7 to $4.1 \mathrm{~s}$ before the initial (morphine) test and from 4.8 to $5.3 \mathrm{~s}$ before the second (saline) test. There were no significant differences between the baseline latencies of the groups on either baseline determination $(F \mathrm{~s}<2.5)$.

The mean tail-flick latencies for rats in the three groups injected with either MK-801 or vehicle and then with morphine are shown on the left side of Figure 3. Inspection of this side suggests that rats in the paired group injected with vehicle responded with faster tail-flick latencies than did rats in the unpaired and naive groups. Moreover, this associatively mediated reduction in morphine analgesia appeared to have been reversed by an injection of MK-801. However, this effect of MK-801 was not specific to rats in the paired group because MK-801 increased the levels of morphine analgesia for rats in the unpaired group. These observations were confirmed by the statistical analysis. There was evidence for an associatively mediated reduction in morphine's analgesic effects averaged over MK-801 and saline, as rats in the paired group responded with significantly faster tail-flick latencies than did those in the unpaired and naive groups, $F(1,42)=17.4, F_{c}=4.0$. There were no significant differences between the tail-flick latencies of rats in the unpaired and naive groups $(F=2.8)$. Rats injected with vehicle showed significantly faster tail-flick latencies than did rats injected with MK-801 $(F=5.5)$. Importantly, there were significant interactions between the contrasts assessing differences between the tail-flick latencies of MK-801 and vehicle-treated rats and the contrasts testing for differences between the paired group versus the control groups $(F=4.6)$ and the unpaired group versus the naive group $(F=5.6)$. A post hoc contrast revealed that the differences between MK-801 and vehicle-treated rats were not significantly greater among rats in the paired and unpaired groups $(F<1.0)$. Thus, a systemic injection of MK-801 increased the levels of morphine analgesia for rats in both the paired and unpaired groups but not for rats in the naive group, indicating that $\mathrm{MK}-801$ interacted with a history of morphine exposure to reinstate morphine's analgesic effect for rats in the paired group and to increase this effect for those in the unpaired group (cf. Grisel et al., 1996).

The mean tail-flick latencies for rats in the three groups injected with either MK-801 or vehicle and then with saline are shown on the right side of Figure 3. Inspection of this side suggests that, whereas rats in the paired group tested with vehicle responded with faster tail-flick latencies than did those in the unpaired and naive groups, these differences in tail-flick latencies were reversed by systemic MK-801. The statistical analysis confirmed evidence for an associatively mediated hyperalgesia averaged over MK-801 and saline because rats in the paired group responded with

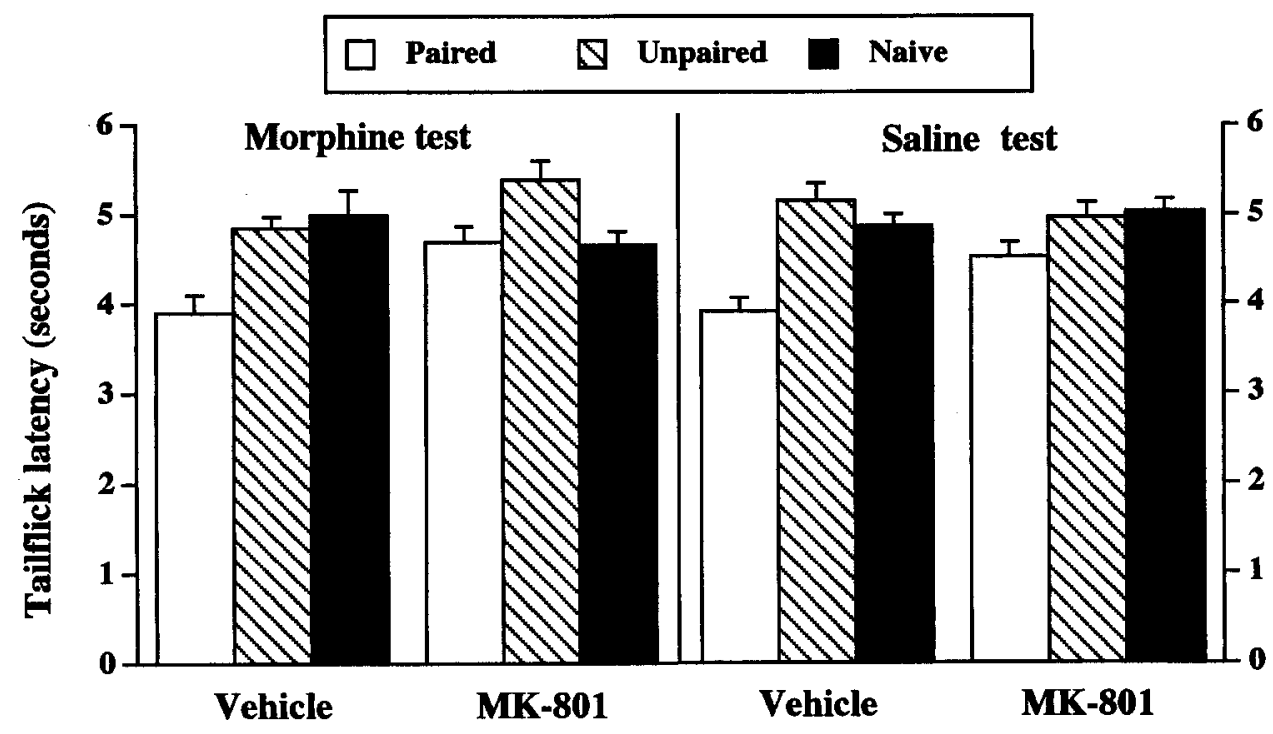

Figure 3. Left panel: Mean and standard error of the mean tail-flick latencies following tail immersion in a $53^{\circ} \mathrm{C}$ waterbath during the morphine test in Experiment 2. Right panel: Mean and standard error of the mean tail-flick latencies following tail immersion in a $51{ }^{\circ} \mathrm{C}$ waterbath during the saline test in Experiment 2. Rats were tested after systemic injection of MK-801 $(0.1 \mathrm{mg} / \mathrm{kg})$ or vehicle. 
significantly faster latencies than did those in the unpaired and naive groups, $F(1,42)=33.0, F_{\mathrm{c}}=4.0$. There were no significant differences between the latencies of rats in the unpaired and naive groups $(F<1)$. There also was no evidence for an overall effect of MK-801 versus vehicle on tail-flick latencies averaged across training conditions $(F=2.2)$. Importantly, there was a significant interaction between the contrast assessing differences between tail-flick latencies for rats in the paired group versus those shown by rats in the control groups and the contrast assessing differences between MK-801 and vehicle-treated rats $(F=5.1)$. Thus, MK-801 reversed the associatively mediated hyperalgesia shown by rats in the paired group. Moreover, this reversal was specific to the effects of MK-801 on that hyperalgesia because there was no significant interaction between the contrast assessing differences between tail-flick latencies of rats in the unpaired and naive groups and that assessing the differences between MK-801 and vehicle $(F=1.3)$.

The results of this experiment confirm that a flavor paired with morphine can mediate morphine analgesic tolerance (Experiment 1a) and provoke a hyperalgesic response (Experiment $1 \mathrm{~b}$ ). We also found that both of these effects were reversed by systemic injection of MK-801. However, the specificity of action by MK-801 differed with respect to these two effects. Specifically, MK-801 reinstated morphine analgesia for rats in the paired group, suggesting a role for NMDA receptors in associative tolerance. However, MK801 also increased the levels of morphine analgesia for rats in the unpaired group, indicating that there may have been some undetected level of nonassociative tolerance that was reversed by the NMDA receptor antagonist (Grisel et al., 1996). This increased analgesia could mean that MK-801 reversed the associative tolerance exhibited by rats in the paired group as well as the nonassociative tolerance taken to have been developed by those in the unpaired group. Alternatively, MK-801 may have acted selectively on the nonassociative tolerance developed by rats in both the unpaired and paired groups, but not on the associative tolerance acquired by rats in the paired group. In contrast to these findings with rats tested under morphine, MK-801 reversed the associatively mediated hyperalgesia shown by rats in the paired group without provoking an increase in basal nociceptive sensitivity for rats in the unpaired and naive groups.

\section{Experiments $3 \mathrm{a}$ and $3 \mathrm{~b}$}

In these experiments we investigated the involvement of supraspinal NMDA receptors in the expression of associatively mediated morphine analgesic tolerance and hyperalgesia. Rats in the paired, unpaired, and naive groups were trained according to the same schedule as had been used previously and were tested after an intraoral infusion of saccharin. In Experiment 3a, rats were tested under morphine, whereas in Experiment $3 \mathrm{~b}$ rats were tested under saline. On the test in each experiment, half of the rats from each of the three groups were microinjected with the competitive NMDA antagonist AP-5 into the right lateral ventricle, whereas the remainder received an intracerebroventricular microinjection of vehicle. These experiments were conducted separately but are reported together for convenience of exposition.

\section{Method}

\section{Subjects and Apparatus}

Subjects were experimentally naive adult male Wistar rats weighing between 300 and $400 \mathrm{~g}$. Rats were obtained from the same source and maintained under the conditions described previously. The apparatus was that used in the previous experiments.

\section{Drugs}

Morphine was injected at the dose and volume used in Experiment 2. An isotonic saline solution was used for control injection. AP-5 (Sigma Chemical, Sydney, Australia) was diluted in sterile nonpyrogenic saline $(0.9 \% \mathrm{wt} / \mathrm{vol})$ to obtain a concentration of 5.0 $\mu \mathrm{g} / 3.0 \mu \mathrm{l}$. For intracerebroventricular microinjections, AP-5 or saline was injected in a volume of $3.0 \mu \mathrm{l}$. A solution was microinjected across a $1-\mathrm{min}$ period and the microinjection cannula left in place for another minute to permit diffusion. This dose of AP-5 was selected for intracerebroventricular microinjection because it has been shown to disrupt the acquisition of conditioned fear responses (freezing) to a context where rats were shocked (Fanselow, Kim, Yipp, \& De Oca, 1994; Kim, Fanselow, DeCola, \& Landeira-Fernandez, 1992).

\section{Procedure}

Five days before the beginning of the experiment, rats were handled each day and placed on the fluid deprivation regimen described previously apart from the first 3 days postoperatively, when access to water was unlimited.

Training. Across Days 1-11, the rats in the three groups were trained according to the procedure described in Experiments 1a and $1 \mathrm{~b}$.

Surgery. Intracranial cannulas were implanted on Day 12, 48 $\mathrm{hr}$ after the last saccharin exposure. Before surgery, the rats were injected with a prophylactic dose of $0.35 \mathrm{ml}$ of a $300.0-\mathrm{mg} / \mathrm{ml}$ solution of procaine penicillin. They were then injected intraperitoneally with $1.3 \mathrm{ml} / \mathrm{kg}$ of the anesthetic ketamine at a concentration of $100.0 \mathrm{mg} / \mathrm{ml}$ and with $0.3 \mathrm{ml} / \mathrm{kg}$ of the muscle relaxant xylazine at a concentration of $20.0 \mathrm{mg} / \mathrm{ml}$. After its head had been shaved, each rat was placed in the stereotaxic instrument (Kopf, Model 900 , Tujunga, CA) while maintaining the incisor bar at approximately $3.3 \mathrm{~mm}$ below horizontal to achieve a flat skull position. A 22-gauge guide cannula (Plastics One, Roanoke, VA) was aimed to terminate $0.5 \mathrm{~mm}$ dorsal to the right lateral ventricle by positioning it $3.0 \mathrm{~mm}$ ventral to bregma through a hole drilled $0.8 \mathrm{~mm}$ posterior and $1.5 \mathrm{~mm}$ lateral to bregma. During drug infusion, the 26-gauge microinjection cannula projected another $1 \mathrm{~mm}$ ventral to the tip of the guide, terminating in the ventricle. The microinjection cannula was connected to a $25.0-\mu \mathrm{l}$ Hamilton glass syringe operated by an infusion pump (Harvard Apparatus, South Natick, MA). The guide cannula was fixed in position with dental cement and anchored by three jeweler's screws. A dummy cannula was kept in place at all other times except during infusion. Across Days 13-17, the rats were allowed to recover from surgery. At the end of each 
experiment rats were given an overdose of sodium pentobarbital, and their brains removed. Unfixed brains were sectioned coronally at $40 \mu \mathrm{m}$ using a cryostat and stained with cresyl violet to determine the location of the cannulas. Rats whose microinjection cannula tips were more than $0.5 \mathrm{~mm}$ outside the ventricle were excluded from the analysis (Paxinos \& Watson, 1986).

Familiarization. Across Days 18-19, all rats were familiarized with the test apparatus in the manner described for Experiments 1a and $1 \mathrm{~b}$.

Tail-fick test under morphine. On Day 20, the rats in Experiment $3 a$ were transported to the laboratory and placed in the plastic buckets for $20 \mathrm{~min}$. Baseline latencies were determined in the manner described previously, with the temperature of the waterbath at $53{ }^{\circ} \mathrm{C}$. Rats were microinjected with AP-5 (paired group, $n=6$; unpaired group, $n=7$; and naive group, $n=7$ ) or its vehicle (paired group, $n=7$; unpaired group, $n=6$; and naive group, $n=8) 10 \mathrm{~min}$ after the final baseline trial. Five min after microinjection, the rats received an intraoral infusion of $0.3 \mathrm{ml}$ saccharin, which was followed $5 \mathrm{~min}$ later by an intraperitoneal injection of morphine. Five minutes after injection of morphine, tail-flick testing began and was repeated once every $5 \mathrm{~min}$ for another $50 \mathrm{~min}$.

Tail-flick test under saline. On Day 20, the rats in Experiment $3 \mathrm{~b}$ were transported to the laboratory and placed in the plastic buckets for $20 \mathrm{~min}$. Baseline latencies were determined in the manner described previously, with the waterbath temperature maintained at $51{ }^{\circ} \mathrm{C}$. Rats were microinjected with AP-5 (paired group, $n=8$; unpaired group, $n=8$; and naive group, $n=7$ ) or its vehicle (paired group, $n=7$; unpaired group, $n=7$; and naive group, $n=8$ ) $10 \mathrm{~min}$ after the final baseline trial. Five minutes after microinjection, the rats received an intraoral infusion of 0.3

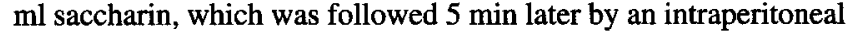
injection of saline. Five minutes after the injection of saline, tail-flick testing began and was repeated once every $5 \mathrm{~min}$ for another $50 \mathrm{~min}$.

\section{Results}

Statistical analysis confirmed that rats in the paired group had learned to suppress saccharin intake: In Experiment 3a, they drank significantly less saccharin $(M=5.1 \mathrm{ml})$ on the third training trial than did rats in the unpaired $(M=19.0$ $\mathrm{ml})$ and naive $(M=21.7 \mathrm{ml})$ groups, $F(1,36)=165.4, F_{\mathrm{c}}=$ 4.2, whose intakes did not differ from each other $(F=2.4)$. In Experiment $3 \mathrm{~b}$, rats in the paired group drank significantly less saccharin $(M=5.0 \mathrm{ml})$ than those in the unpaired $(M=16.4 \mathrm{ml})$ and naive $(M=17.6 \mathrm{ml})$ groups, $F(1,40)=$ $116.4, F_{\mathrm{c}}=4.1$, whose intakes again did not differ from each other $(F=1.2)$. Mean baseline latencies ranged from 3.7 to $4.0 \mathrm{~s}$ before the morphine test conducted in Experiment 3a and from 4.5 to $4.8 \mathrm{~s}$ before the saline test administered in Experiment 3b. There were no significant differences between groups in baseline latencies in either experiment $(F \mathrm{~s}<1.2)$.

The mean tail-flick latencies for rats in the three groups in Experiment $3 \mathrm{a}$ who received either an intracerebroventricular microinjection of AP-5 or vehicle and were then injected with morphine are shown in the left side of Figure 4. Inspection of this side suggests that rats in the paired group microinjected with vehicle responded with faster tail-flick latencies than did rats in the unpaired and naive groups. Moreover, this associatively mediated reduction in morphine analgesia did not appear to have been attenuated by microinjection of AP-5. These observations were confirmed by the statistical analysis. Averaged across AP-5 and vehicle, rats in the paired group responded with significantly faster tail-flick latencies than did those in the unpaired and naive groups, $F(1,35)=10.2, F_{\mathrm{c}}=4.1$, confirming the presence of

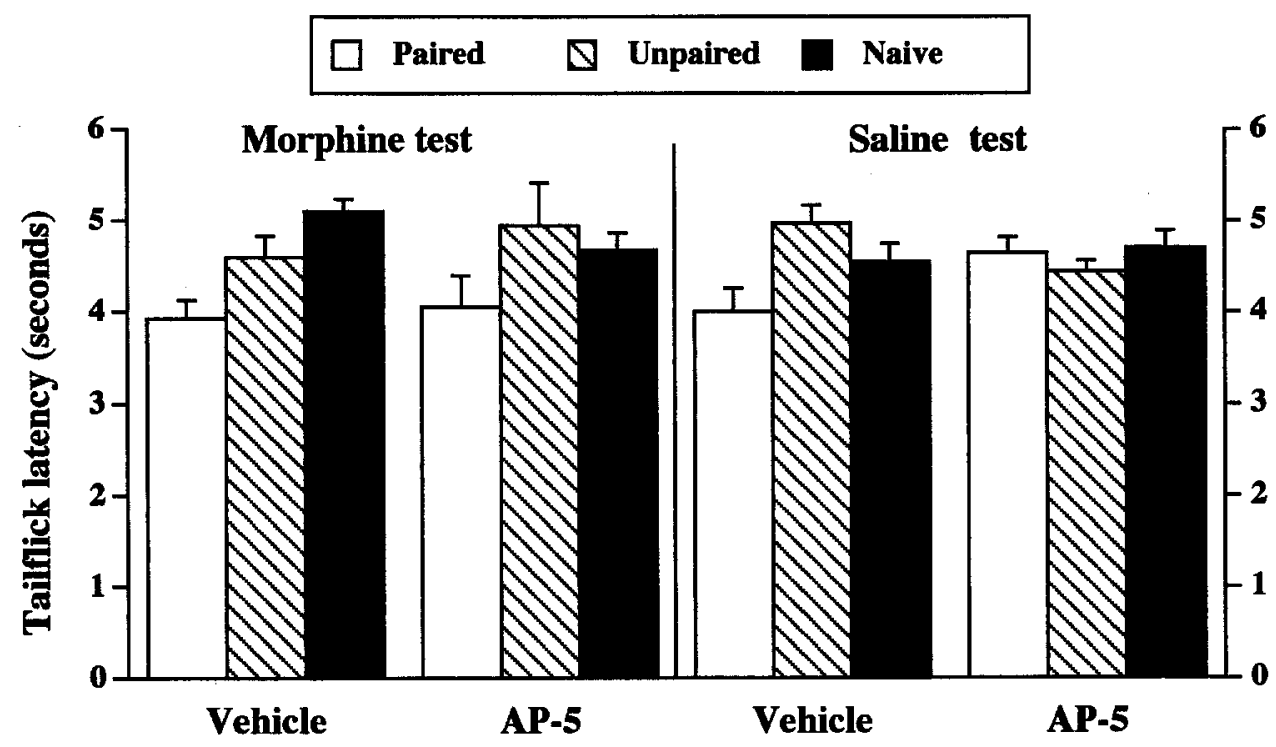

Figure 4. Left panel: Mean and standard error of the mean tail-flick latencies following tail immersion in a $53{ }^{\circ} \mathrm{C}$ waterbath during the morphine test in Experiment 3a. Right panel: Mean and standard error of the mean tail-flick latencies following tail immersion in a $51^{\circ} \mathrm{C}$ waterbath during the saline test in Experiment $3 \mathrm{~b}$. Rats in both experiments were tested after an intracerebroventricular microinjection of $\mathrm{D}, \mathrm{L}-2$-amino-5-phosphonopentanoic acid (AP-5) $(5 \mu \mathrm{g} / 3 \mu \mathrm{l})$ or vehicle $(3 \mu \mathrm{l})$. 
associatively mediated morphine analgesic tolerance. There were no significant differences between the tail-flick latencies of rats in the unpaired and naive groups averaged across AP-5 and vehicle $(F=1.5)$. There were no significant differences between the tail-flick latencies of rats microinjected with AP-5 or vehicle averaged across training conditions $(F<1)$. Finally, there were no significant interactions among training conditions and AP-5 versus vehicle $(F \mathrm{~s}<1)$.

The mean tail-flick latencies for rats in the three groups in Experiment $3 b$ who received either an intracerebroventricular microinjection of AP-5 or vehicle and were then injected with saline are shown on the right side of Figure 4. Inspection of this side suggests that for rats tested with vehicle, those in the paired group responded with faster tail-flick latencies than did rats in the unpaired and naive groups. However, these differences in tail-flick latencies were reversed by microinjection of AP-5. These observations were confirmed by the statistical analysis. Averaged across rats microinjected with AP-5 and vehicle, there were no significant differences between tail-flick latencies of rats in the paired group versus those in the unpaired and naive groups, $F(1,38)=3.9, F_{\mathrm{c}}=4.1$, or between the latencies of rats in the unpaired and naive groups $(F<1)$. Averaged across training groups, there were no significant differences between rats microinjected with AP-5 or vehicle $(F<1)$. There was no evidence for an interaction between unpaired and naive groups and the AP-5 versus vehicle groups $(F=2.8)$. Importantly, however, there was a significant interaction between the paired group versus the unpaired and naive groups and $\mathrm{AP}-5$ versus vehicle $(F=5.4)$. Thus, whereas Experiment 3a showed that an intracerebroventricular microinjection of AP-5 spared associatively mediated morphine analgesic tolerance, Experiment $3 \mathrm{~b}$ revealed that an intracerebroventricular microinjection of AP-5 reversed the hyperalgesia that co-occurs with that tolerance.

\section{Experiments $4 \mathrm{a}$ and $4 \mathrm{~b}$}

In these experiments we investigated the involvement of spinal NMDA receptors in the expression of associatively mediated morphine analgesic tolerance and hyperalgesia. Rats in the paired, unpaired, and naive groups were trained according to the same schedule as had been used previously, implanted with intrathecal catheters, and tested after an intraoral infusion of saccharin. In Experiment 4a, rats were tested under the influence of morphine, whereas in Experiment $4 \mathrm{~b}$ rats were tested after an injection of saline. On the test in each experiment, half of the rats from each of the three groups received an intrathecal infusion of AP-5, whereas the remainder received an intrathecal infusion of vehicle. These experiments were conducted separately but are reported together for convenience of exposition.

\section{Method}

\section{Subjects and Apparatus}

Subjects were experimentally naive adult male Wistar rats weighing between 400 and $500 \mathrm{~g}$. Rats were obtained from the same source and maintained under the conditions described previously. There were 48 rats in Experiment $4 a$ and 60 rats in Experiment $4 \mathrm{~b}$. The apparatus was that used in previous experiments.

\section{Drugs}

Morphine was injected across training and on test at the dose and volume described in Experiment 2. A sterile nonpyrogenic saline solution $(0.9 \% \mathrm{wt} / \mathrm{vol})$ was used for control injections. AP-5 was prepared and infused intrathecally at the dose and volume described in Experiment $3 \mathrm{a}$. Intrathecal infusions of AP-5 and vehicle $(3.0 \mu \mathrm{l}, 0.9 \%$ saline) were followed immediately by infusion of $30.0 \mu \mathrm{l}$ saline over $30 \mathrm{~s}$ to ensure that the drug reached the cord.

\section{Procedure}

Five days before beginning the experiment, rats were handled each day and placed on the fluid deprivation regimen described previously apart from the first 3 days postoperatively, when access to water was unlimited.

Training. Across Days 1-11, the rats in Experiment 4a were trained according to the same procedure described in Experiments $1 \mathrm{a}$ and $1 \mathrm{~b}$. Rats in Experiment $4 \mathrm{~b}$ received an additional training trial $96 \mathrm{hr}$ after the third trial because 2 rats in the paired group did not acquire a significant flavor avoidance as measured during the third trial.

Surgery. Intrathecal catheters were implanted on Day 12 (Experiment 4a) or Day 16 (Experiment $4 \mathrm{~b}$ ) $48 \mathrm{hr}$ after the last saccharin exposure. Before surgery, the rats were injected with a prophylactic dose of $0.35 \mathrm{ml}$ of a $300.0-\mathrm{mg} / \mathrm{ml}$ solution of procaine penicillin. Intrathecal surgery was performed using a modification of the procedure described by Storkson, Kjorsvik, Tjolsen, and Hole (1996). Each rat was anesthetized according to the procedure used in Experiments $3 \mathrm{a}$ and $3 \mathrm{~b}$, and an 18-gauge guide cannula was inserted between the L5 and L6 vertebrae. Sterile polyethylene tubing was inserted through the guide cannula and advanced $3.0 \mathrm{~cm}$ rostrally beyond its tip to terminate in the lumbar enlargement. The catheter was secured to the superficial muscle of the back and then tunneled subcutaneously to exit in the dorsal neck region, where it was secured to the superficial musculature, flushed with sterile isotonic saline, and heat sealed. Correct intrathecal placement was verified at the time of surgery by tail-flick or paw retraction and at the conclusion of the experiments by intrathecal infusion of $10.0 \mu$ of $2.0 \%$ lidocaine producing a temporary paralysis of the hindquarters. Across the subsequent 5 days, the rats were allowed to recover from surgery.

Familiarization. Across Days 18 and 19 (Experiment 4a) or Days 22 and 23 (Experiment 4b), all rats were familiarized with the test apparatus in the manner described for Experiments $1 \mathrm{a}$ and $1 \mathrm{~b}$.

Tail-flick test under morphine. On Day 20, the rats in Experiment $4 \mathrm{a}$ were transported to the laboratory and placed in the plastic buckets for $20 \mathrm{~min}$. Baseline latencies were determined in the manner described previously, with the temperature of the waterbath maintained at $53^{\circ} \mathrm{C}$. Rats received an intrathecal infusion of AP-5 (paired group, $n=7$; unpaired group, $n=7$; and naive group, $n=6$ ) or its vehicle (paired group, $n=7$; unpaired group, $n=8$; and naive group, $n=6$ ) $10 \mathrm{~min}$ after the final baseline trial. Five minutes after microinjection, rats received an intraoral infusion of $0.3 \mathrm{ml}$ saccharin, which was followed $5 \mathrm{~min}$ later by an intraperitoneal injection of morphine. Five minutes after injection of morphine, tail-flick testing began and was repeated once every $5 \mathrm{~min}$ for another $50 \mathrm{~min}$.

Tail-flick test under saline. On Day 24, the rats in Experiment $4 \mathrm{~b}$ were transported to the laboratory and placed in the plastic 
buckets for $20 \mathrm{~min}$. Baseline latencies were determined in the manner described previously, with the temperature of the waterbath maintained at $51^{\circ} \mathrm{C}$. Rats received an intrathecal infusion of AP-5 (paired group, $n=8$; unpaired group, $n=8$; and naive group, $n=9$ ) or its vehicle (paired group, $n=9$; unpaired group, $n=10$; and naive group, $n=9$ ) $10 \mathrm{~min}$ after the final baseline trial. Five minutes after microinjection, rats received an intraoral infusion of $0.3 \mathrm{ml}$ saccharin, which was followed $5 \mathrm{~min}$ later by an intraperitoneal injection of saline. Five minutes after injection of saline, tail-flick testing began and was repeated once every $5 \mathrm{~min}$ for another $50 \mathrm{~min}$.

Pilot studies revealed that an intrathecal infusion of AP-5 produced a small hypoalgesic and motoric effect that persisted for approximately $25 \mathrm{~min}$ after infusion. To avoid this confounding influence on interpretation, we report only the data from the six tail-flick trials conducted over the last $30 \mathrm{~min}$ of test in both experiments.

\section{Results}

Statistical analysis confirmed that rats in the paired group had learned to suppress saccharin intake in both experiments. On the final training trial in Experiment 4a, the rats in the paired group drank significantly less saccharin $(M=4.9$ ml) than did those in the unpaired $(M=16.8 \mathrm{ml})$ and naive $(M=16.5 \mathrm{ml})$ groups, $F(1,37)=42.0, F_{\mathrm{c}}=4.1$, whose intakes did not differ from each other $(F<1)$. On the final training trial in Experiment $4 b$, rats in the paired group drank significantly less saccharin $(M=7.7 \mathrm{ml})$ than did those in the unpaired $(M=16.2 \mathrm{ml})$ and naive $(M=17.9 \mathrm{ml})$ groups, $F(1,48)=89.7, F_{\mathrm{c}}=4.0$, whose intakes did not differ from each other $(F=2.47)$. Baseline latencies ranged from 4.3 to $5.1 \mathrm{~s}$ before the morphine test in Experiment $4 \mathrm{a}$ and from 4.3 to $5.0 \mathrm{~s}$ before the saline test in Experiment $4 \mathrm{~b}$.
There were no significant differences between groups in baseline latencies in either experiment $(F \mathrm{~s}<2.45)$.

The mean tail-flick latencies for rats in the three groups in Experiment $4 \mathrm{a}$ who received either an intrathecal infusion of AP-5 or vehicle and were then injected with morphine are shown on the left side of Figure 5. Inspection of this side suggests that rats in the paired group responded with faster tail-flick latencies than did those in the control groups and that these differences were attenuated by AP-5. The statistical analysis revealed that there were no significant differences between the tail-flick latencies of rats in the paired group compared with those in the unpaired and naive groups, $F(1,34)<1, F_{\mathrm{c}}=4.1$, or between those of rats in the unpaired and naive groups $(F<1)$, averaged across AP-5 and vehicle, or between the latencies of rats infused with AP-5 or vehicle $(F<1)$. There was no significant interaction between the unpaired versus naive group and AP-5 versus vehicle $(F<1)$. Importantly, however, there was a significant interaction between the paired group versus the unpaired and naive groups and AP-5 versus vehicle $(F=6.2$ ). Inspection of the left side of Figure 5 shows that the differences between AP-5 and vehicle-treated rats was greatest in the paired group than in the unpaired and naive groups, indicating that an intrathecal infusion of AP-5 abolished associatively mediated morphine analgesic tolerance.

The mean tail-flick latencies for rats in the three groups in Experiment $4 \mathrm{~b}$ who received either an intrathecal infusion of AP-5 or vehicle and were then injected with saline are shown on the right side of Figure 5. Inspection of this side suggests that rats in the paired group were hyperalgesic compared with those in the unpaired and naive groups and

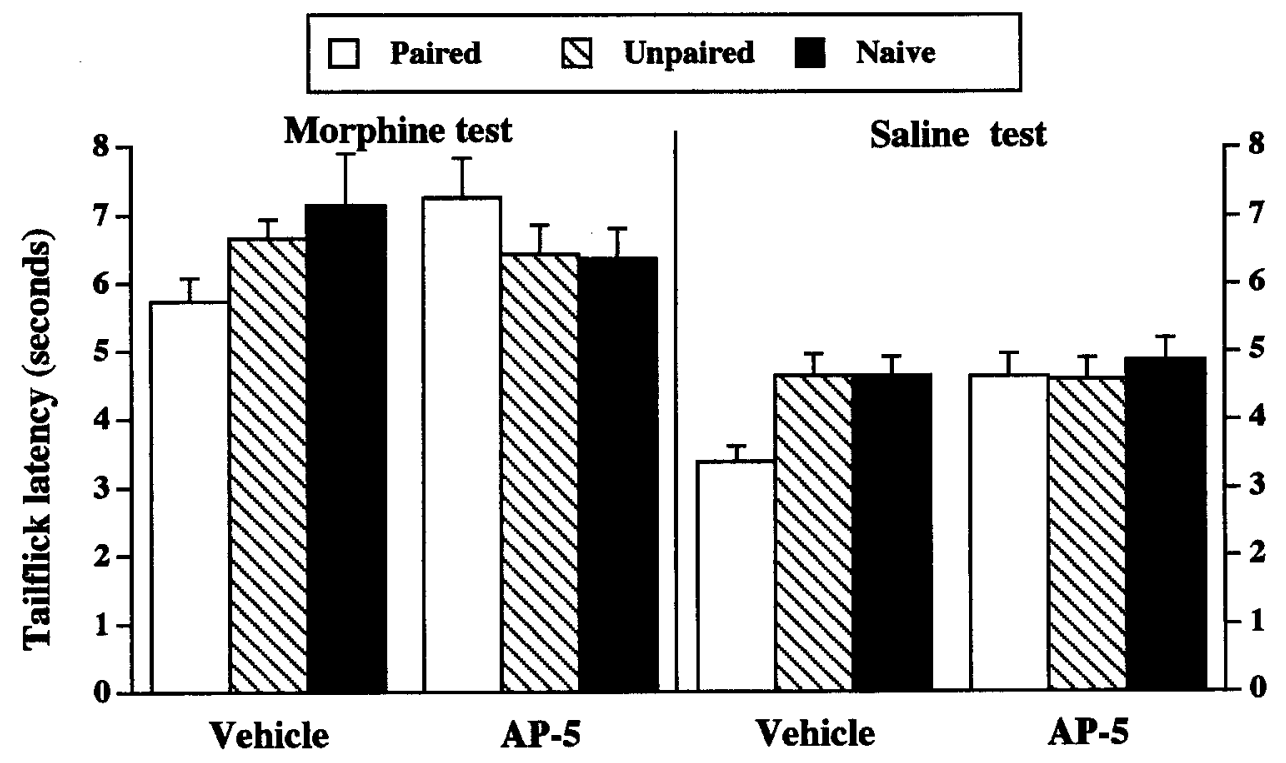

Figure 5. Left panel: Mean and standard error of the mean tail-flick latencies following tail immersion in a $53{ }^{\circ} \mathrm{C}$ waterbath during the morphine test in Experiment 4a. Right panel: Mean and standard error of the mean tail-flick latencies following tail immersion in a $51{ }^{\circ} \mathrm{C}$ waterbath during the saline test in Experiment $4 \mathrm{~b}$. Rats in both experiments were tested after an intrathecal infusion of D,L-2-amino-5-phosphonopentanoic acid (AP-5) $(5 \mu \mathrm{g} / 3 \mu \mathrm{l})$ or vehicle $(3 \mu \mathrm{l})$. 
that this hyperalgesia was reversed by an intrathecal infusion of AP-5. The statistical analysis showed that rats in the paired group responded with significantly faster latencies than did those in the unpaired and naive groups, $F(1,46)=$ $6.4, F_{\mathrm{c}}=4.1$, whose latencies did not differ from each other $(F<1)$. Rats infused with AP-5 did not differ in tail-flick latencies from those receiving vehicle $(F=3.7)$, and there was no interaction between the unpaired versus naive group and AP-5 versus vehicle $(F<1)$. Importantly, however, there was a significant interaction between the paired group versus the unpaired and naive groups and AP-5 versus vehicle $(F=4.6)$. Inspection of the right side of Figure 5 shows that the difference between AP-5 and vehicle-treated rats was greatest in the paired group than in the unpaired and naive groups, indicating that an intrathecal infusion of AP-5 had reversed associatively mediated hyperalgesia.

\section{General Discussion}

Our series of experiments has confirmed that associative learning processes can contribute to morphine analgesic tolerance development and has provided evidence that this associatively mediated tolerance is accompanied by a hyperalgesic response. Specifically, a flavor (saccharin) paired with morphine produced a shift to the right in the doseresponse function (Experiment 1a) and provoked hyperalgesia when the flavor was presented and rats were tested in the absence of morphine (Experiment 1b). These learned changes in nociceptive sensitivity were not secondary to changes in tail-skin temperature (Experiment 1c). Rather, the learned changes in nociceptive sensitivity involved the recruitment of spinal NMDA receptors because systemic administration of the noncompetitive NMDA receptor antagonist MK-801 (Experiment 2) or an intrathecal infusion of the competitive NMDA receptor antagonist AP-5 (Experiment 4b) reversed associatively based hyperalgesia, and an intrathecal infusion of AP-5 also reversed associatively based tolerance to morphine analgesia (Experiment 4a). Although both depend on the activation of spinal NMDA receptors, associatively mediated tolerance to morphine analgesia is dissociable from the co-occurring hyperalgesia because microinjection of AP-5 into the lateral ventricle spared associatively based tolerance (Experiment 3a) but reversed the hyperalgesic response (Experiment $3 b$ ).

The evidence reported here was obtained with a flavor whose presentations had been followed by injection of morphine, whereas previous investigations of learned analgesic tolerance have typically correlated exposure to a distinctive context with injections of morphine. However, in both cases, rats displayed shifts to the right in the doseresponse function when tested in the presence of the drug-predictive cues (e.g., Tiffany \& Maude-Griffin, 1988). However, whereas the presentation of the drug-predictive flavor provoked hyperalgesic responses when rats were tested in the absence of morphine, previous demonstrations of context-specific tolerance have persistently failed to detect a hyperalgesic response when rats were exposed to the drug-correlated context and tested in the absence of morphine (e.g., Paletta \& Wagner, 1986; Tiffany, Petrie,
Baker, \& Dahl, 1983). One explanation of these discrepant findings is that there are variations in the contents of what is learned about drug-predictive cues and morphine. For instance, rats injected with a moderate dose of morphine after exposure to a flavor in a distinctive context subsequently avoided the flavor but showed a preference for that context (Bechara \& van der Kooy, 1985; Bechara, Zito, \& van der Kooy, 1987). Moreover, this flavor avoidance was mediated by morphine's actions in the gut because it was abolished by sectioning the subdiaphragmatic branch of the vagus nerve, neonatal destruction of vagal afferents, coadministration of the peripheral opiate receptor antagonist methylnaltrexone, or lesions of the visceral insular cortex (e.g., Bechara \& van der Kooy, 1985; Zito, Bechara, Greenwood, \& van der Kooy, 1988). This explanation then proposes that morphine's aversive effects in the gut or a flavor that signals those aversive effects activates hyperalgesic mechanisms. An alternative explanation of the learned hyperalgesia observed here and previous failures to detect evidence for this learning is that there are constraints at the level of performance of a learned response (see Rescorla, 1988, for a discussion). For instance, both Gallagher and Holland (1992) and Holland $(1977,1984)$ have reported that an auditory or a visual conditioned stimulus (CS) paired with a food unconditioned stimulus (US) elicits common behaviors appropriate to that US (so-called "US-generated behaviors") as well as behaviors that are unique to that particular CS (so-called "CS-generated behaviors"). According to this explanation, associative processes enable morphine-predictive cues (flavors or contexts) to gain access to analgesic tolerance mechanisms, and the particular cues used determine the form of the conditioned responses such that flavors, but not contexts, support the expression of hyperalgesic responses.

The analgesic tolerance mechanisms'activated by a flavor paired with morphine and the hyperalgesic consequences of this flavor-morphine association involve spinal NMDA receptors because both tolerance and hyperalgesia were reversed by an intrathecal infusion of AP-5. These receptors are recruited by repeated exposures to morphine and mediate the tolerance and the hyperalgesia resulting from that morphine experience (e.g., Mao, Price, \& Mayer, 1995). Consequently, our findings indicate that a flavor that signaled the arrival of morphine in the body facilitated adaptation by provoking activity at spinal NMDA receptor sites in advance of their recruitment by morphine. Furthermore, the provision of a flavor that signaled morphine's effects promoted tolerance acquisition under our training regimen in the absence of evidence for that acquisition among rats in the unpaired group with an equivalent but unsignaled history of morphine exposures (e.g., Experiment 1a). However, it seems reasonable to propose that rats in the unpaired group, given more extended training with morphine, would have eventually acquired some level of tolerance and that this tolerance would have been reversed by an NMDA receptor antagonist (e.g., Grisel et al., 1996). Therefore, associative learning processes also may facilitate adaptation by enabling the organism to rapidly engage those spinal pronociceptive mechanisms eventually deployed by the body in response to 
repeated administrations of morphine. Although sharing a common spinal substrate, associatively mediated tolerance and hyperalgesia are dissociable. Specifically, an intracerebroventricular microinjection of AP-5 spared tolerance but reversed hyperalgesia. This dissociation may reflect differences in the supraspinal mechanisms whose descending projections engage the same spinal processes or of neurochemical differences within the same circuitry. However, irrespective of the nature of these differences, our demonstration of a dissociation between associatively mediated analgesic tolerance and hyperalgesia is inconsistent with the claim that the acquisition of a hyperalgesic response by drugpredictive cues is critical to the development of associatively mediated analgesic tolerance (cf. Siegel, 1975, 1989). Rather, this dissociation is consistent with the view that there are multiple mechanisms for associatively mediated tolerance and hyperalgesia (see Paletta \& Wagner, 1986, for a discussion).

Finally, note that prolonged ingestion of sweet flavors can reduce the analgesic effectiveness of morphine. For instance, rats exposed for $24 \mathrm{hr}$ to a glucose-saccharin solution subsequently showed faster paw-lick latencies when tested in a hot plate apparatus under morphine than did control rats preexposed to water (Holder, 1988). Moreover, rats given continuous access to a dextrose-saccharin solution across 18 days may have been rendered hyperalgesic as a consequence of this experience because they displayed faster paw-lick latencies than did rats preexposed to water (Holder \& Bolger, 1988). There also is some evidence for decreases in opioid agonist binding affinity in rats given prolonged access to sweet or calorically rich solutions (e.g., Dum, Gramsch, \& Herz, 1983; however, see Holder \& Bolger, 1988). These findings raise the possibility that the use of saccharin in our experiments may have triggered activity in an opioid system that modulates the analgesic effectiveness of morphine and that blockade of NMDA receptors may have disrupted this modulation. Although this needs to be acknowledged as a possible contributing factor to the findings reported here, it is important to note that (a) saccharin provoked tolerance and hyperalgesia in the paired group compared with the performances displayed by the unpaired group and (b) rats in these groups and in the naive group were tested after the intraoral infusion of a relatively small amount of saccharin. Moreover, if presentations of saccharin followed by injections of morphine had provoked greater changes in opioid binding activity than separate presentations of saccharin and morphine, rats in the paired group should have persistently shown hyperalgesia compared with those in the unpaired group when tested in the absence of saccharin. However, the results from the baseline assessments for basal nociceptive sensitivity before the test presentations of saccharin failed to reveal such differences in each of the experiments reported.

\section{References}

Bechara, A., \& van der Kooy, D. (1985). Opposite motivational effects of endogenous opioids in brain and periphery. Nature, $314,533-534$.
Bechara, A., Zito, K. A., \& van der Kooy, D. (1987). Peripheral receptors mediate the aversive effects of morphine in the rat. Pharmacology Biochemistry and Behavior, 28, 219-225.

Berge, O.-G., Garcia-Cabrera, I., \& Hole, K. (1988). Response latencies in the tailflick test depend on tailskin temperature. Neuroscience Letters, 86, 284-288.

Boik, R. J. (1981). A priori tests in repeated measures designs: Effects of non-sphericity. Psychometrika, 46, 241-255.

Coderre, T. J., Katz, J., Vaccarino, A. L., \& Melzack, R. (1993). Contribution of central neuroplasticity to pathological pain. Pain, 52, 259-285.

Cohen, J., \& Cohen, P. (1975). Applied multiple regression/ correlational analysis for the behavioral sciences. Hillsdale, NJ: Erlbaum.

Dum, J., Gramsch, C., \& Herz, A. (1983). Activation of hypothalamic beta-endorphin pools by reward induced by highly palatable food. Pharmacology Biochemistry and Behavior, 18, 443447.

Dunbar, S., \& Yaksh, T. L. (1996). Concurrent spinal infusion of MK-801 blocks spinal tolerance and dependence induced by chronic intrathecal morphine in the rat. Anaesthesiology, 84, 1177-1188.

Elliott, K., Minami, N., Kolesnikov, Y. A., Pasternak, G. W., \& Inturrisi, C. E. (1994). The NMDA receptor antagonists, LY274614 and MK-801, and the nitric oxide synthase inhibitor, NG-nitro-L-arginine, attenuate analgesic tolerance to the muopioid morphine but not kappa opioids. Pain, 56, 69-75.

Fanselow, M. S., Kim, J. J., Yipp, J., \& De Oca, B. (1994). Differential effects of the $N$-methyl-D-aspartate antagonist DL-2amino-5-phosphonovalerate on acquisition of fear of auditory and contextual cues. Behavioral Neuroscience, 108, 235-240.

Fields, H. L., \& Basbaum, A. I. (1994). Central nervous system mechanisms of pain modulation. In P. D. Wall \& R. Melzack (Eds.), Textbook of pain (pp. 243-257). Edinburgh, Scotland: Churchill Livingstone.

Gallagher, M., \& Holland, P. C. (1992). Understanding the function of the central nucleus: Is simple conditioning enough. In J. P. Aggleton (Ed.), The amygdala: Neurobiological aspects of emotion, memory and mental dysfunction (pp. 307-321). New York: Wiley-Liss.

Grisel, J. E., Watkins, L. R., \& Maier, S. F. (1996). Associative and non-associative mechanisms of morphine analgesic tolerance are neurochemically distinct in the rat spinal cord. Psychopharmacology, 128, 248-255.

Hays, W. L. (1972). Statistics for the social sciences. New York: Holt, Rinehart \& Winston.

Holder, M. D. (1988). Responsivity to pain in rats changed by ingestion of flavored water. Behavioral and Neural Biology, 49, 45-53.

Holder, M. D., \& Bolger, G. T. (1988). Chronic sweet intake lowers pain thresholds without changing brain mu- or delta-opiate receptors. Behavioral and Neural Biology, 50, 335-343.

Hole, K., \& Tjolsen, A. (1993). The tailflick and formalin tests in rodents: Changes in skin temperature as a confounding factor. Pain, 53, 247-252.

Holland, P. C. (1977). Conditioned stimulus as a determinant of the form of the Pavlovian conditioned response. Journal of Experimental Psychology: Animal Behavior and Processes, 3, 77-104.

Holland, P. C. (1984). Origins of behavior in Pavlovian conditioning. Psychology of Learning and Motivation, 18, 129-174.

Kalant, H., LeBlanc, A. E., \& Gibbins, R. J. (1971). Tolerance to and dependence on some nonopiate psychotropic drugs. Pharmacological Reviews, 23, 135-191.

Kim, J. J., Fanselow, M. S., DeCola, J. P., \& Landeira-Fernandez, J. (1992). Selective impairment of long-term but not short-term 
conditional fear by the NMDA antagonist APV. Behavioral Neuroscience, 106, 591-596.

Maier, S. F., Wiertelak, E. P., \& Watkins, L. R. (1992). Endogenous pain facilitory systems: Antianalgesia and hyperalgesia. American Pain Society Journal, 1, 191-198.

Mao, J., Price, D. D., \& Mayer, D. J. (1994). Thermal hyperalgesia in association with the development of morphine tolerance in rats: Role of excitatory amino-acid receptors and protein kinase C. Journal of Neuroscience, 14, 2301-2312.

Mao, J., Price, D. D., \& Mayer, D. J. (1995). Mechanisms of hyperalgesia and morphine tolerance: A current view of their possible interactions. Pain, 62, 259-274.

Marek, P., Ben-Eliyahu, S., Gold, M., \& Liebeskind, J. C. (1991). Excitatory amino acid antagonists (kynurenic acid and MK-801) attenuate the development of morphine analgesic tolerance in the rat. Brain Research, 547, 77-81.

Marek, P., Ben-Eliyahu, S., Vaccarino A. L., \& Liebeskind, J. C. (1991). Delayed application of MK-801 attenuates the development of morphine tolerance in rats. Brain Research, 558, 163-165.

McMahon, S. B., Lewin, G. R., \& Wall, P. D. (1993). Central hyperexcitability triggered by noxious inputs. Current Opinion in Neurobiology, 3, 602-610.

Meller, S. T., \& Gebhart, G. F. (1993). Nitric oxide (NO) and nociceptive processing in the spinal cord. Pain, 52, 127-136.

Paletta, M. S., \& Wagner, A. R. (1986). Development of contextspecific tolerance to morphine: Support for a dual process interpretation. Behavioural Neuroscience, 100, 611-623.

Paxinos, G., \& Watson, C. (1986). The rat brain in stereotaxic coordinates (2nd ed.). San Diego, CA: Academic Press.

Rescorla, R. A. (1988). Pavlovian conditioning: It's not what you think it is. American Psychologist, 43, 151-160.

Siegel, S. (1975). Evidence from rats that morphine tolerance is a learned response. Journal of Comparative and Physiological Psychology, 89, 498-506.

Siegel, S. (1989). Pharmacological conditioning and drug effects. In A. J. Goudie \& M. W. Emmett-Oglesby (Eds.), Psychoactive drugs: Tolerance and sensitization (pp. 115-180). Clifton, NJ: Humana Press.

Storkson, R. V., Kjorsvik, A., Tjolsen, A., \& Hole, K. (1996). Lumbar catheterization of the spinal subarachnoid space in the rat. Journal of Neuroscience Methods, 65, 167-172.

Tiffany, S. T., \& Maude-Griffin, P. M. (1988). Tolerance to morphine in the rat: Associative and nonassociative effects. Behavioral Neuroscience, 102, 534-543.

Tiffany, S. T., Petrie, E. C., Baker, T. B., \& Dahl, J. L. (1983). Conditioned morphine tolerance in the rat: Absence of a compensatory response and cross tolerance with stress. Behavioral Neuroscience, 97, 335-353.

Tjolsen, A., Berge, O.-G., Eide, P. K., Borch, O. J., \& Hole, K. (1988). Apparent hyperalgesia after lesions of the descending serotonergic pathway is due to increased tailskin temperature. Pain, 33, 225-231.

Trujillo, K. A., \& Akil, H. (1991). Inhibition of morphine tolerance and dependence by the NMDA receptor antagonist MK-801. Science, 251, 85-87.

Watkins, L. R., Wiertelak, E. P., Furness, L. E., \& Maier, S. F. (1994). Illness-induced hyperalgesia is mediated by spinal neuropeptides and excitatory amino acids. Brain Research, 664, 17-24.

Watkins, L. R., Wiertelak, E. P., Goehler, L. E., Mooney-Heiberger, K., Martinez, J., Furness, L., Smith, K. P., \& Maier, S. F. (1994). Neurocircuitry of illness-induced hyperalgesia. Brain Research, 639, 283-299.

Wiertelak, E. P., Furness, L., Horan, R., Martinez, J., Maier, S. F., \& Watkins, L. R. (1994). Subcutaneous formalin produces centrifugal hyperalgesia at a non-injected site via the NMDA-nitric oxide cascade. Brain Research, 649, 19-26.

Wiertelak, E. P., Furness, L. E., Watkins, L. R., \& Maier, S. F. (1994). Illness-induced hyperalgesia is mediated by a spinal NMDA-nitric oxide cascade. Brain Research, 664, 9-16.

Wiertelak, E. P., Smith, K. P., Furness, L., Mooney-Heiberger, K., Mayr, T., Maier, S. F., \& Watkins, L. R. (1994). Acute and conditioned hyperalgesic responses to illness. Pain, 56, 227234.

Wilcox, G. L. (1993). Spinal mechanisms of nociceptive transmission and hyperalgesia: Relationships among synaptic plasticity, analgesic tolerance and blood flow. American Pain Society Journal, 2, 265-275.

Willis, W. D., \& Coggeshall, R. E. (1991). Sensory mechanisms of the spinal cord. New York: Plenum.

Yaksh, T. L., Al-Rodham, N. R. F., \& Jensen, T. S. (1988). Sites of action of opiates in the production of analgesia. In H. L. Fields \& J.-M. Besson (Eds.), Progress in brain research (pp. 371-393). Amsterdam: Elsevier.

Zito, K. A., Bechara, A., Greenwood, C., \& van der Kooy, D. (1988). The dopamine innervation of the visceral cortex mediates the aversive effects of opiates. Pharmacology Biochemistry and Behavior, 30, 693-699.

Received July 10, 1997

Revision received December 16, 1997 Accepted February 10, 1998 